\title{
IDENTIFICAÇÃO DE RELEVANTES CAPTURAS FLUVIAIS NOS DIVISORES DE GRANDES BACIAS HIDROGRÁFICAS NO ESTADO DE MINAS GERAIS: ESTUDOS PRELIMINARES
}

\author{
Celina Magalhães ${ }^{(a)}$, Lívia Geoffroy ${ }^{(b)}$, André Salgado ${ }^{(c)}$ \\ (a) Instituto de Geociências/UFMG, celina.cenni@gmail.com \\ (b) Instituto de Geociências/UFMG, liviageoffroy@gmail.com \\ (c) Departamento de Geografia, Instituto de Geociências/UFMG, geosalgado@yahoo.com.br
}

EIXO: SISTEMAS GEOMORFOLÓGICOS: ESTRUTURAS, DINÂMICAS E PROCESSOS

Resumo

Em áreas serranas capturas fluviais são fenômenos gerados pelo avanço das cabeceiras de maior energia sobre as de menor energia. Apesar de ser um processo recorrente e de grande importância ambiental, no Brasil, constitui um fenômeno ainda muito pouco estudado. Nesse trabalho realizouse um estudo através de cartografia e de técnicas de sensoriamento remoto buscando evidências de capturas fluviais nos limites das principais bacias hidrográficas de Minas Gerais. Os resultados, apesar de preliminares, mostram a possibilidade de sete capturas fluviais nas bordas entre cinco das principais bacias hidrográficas do estado: Bacia do Paraná, São Francisco, Doce, Jequitinhonha e Mucuri. Deste modo comprova-se a necessidade de aprofundamento de estudos sobre o tema.

Palavras chave: Capturas fluviais. Bacias Hidrográficas de Minas Gerais. Evolução do Relevo. Sensoriamento Remoto.

\section{Introdução}

Em áreas serranas caracterizadas por degraus no relevo, boa parte das capturas fluviais pode ser compreendida como fenômenos gerados pelo avanço das cabeceiras de maior energia, que drenam a frente das escarpas, sobre as de menor energia, que drenam os planaltos superiores (Cherem et al., 2013). A alteração do nível de base da área capturada modifica intensamente as paisagens, já que essa tende a ser rebaixada até o nível da bacia pirata, causando a regressão das escarpas. Além disso, as capturas fluviais alteram a dinâmica dos rios, modificando as condições ambientais das áreas afetadas. Pouca atenção, porém, tem sido dada ao mapeamento dessas capturas e sua dinâmica.

Neste contexto insere-se o presente trabalho que objetivou, de forma preliminar e baseado apenas em sensoriamento remoto, identificar evidências de grandes capturas fluviais nos limites entre as principais bacias hidrográficas do estado de Minas Gerais. As técnicas utilizadas incluíram a observação de cotovelos de captura e análise de perfis altimétricos pela ferramenta Google Earth(R). 


\section{Caracterização da área}

O Estado de Minas Gerais se localiza na porção centro-sul do Brasil. Possui grande diversidade de substratos litológicos que conjugados com diferentes comportamentos tectônicos e estruturais fornecem a base para uma grande diversidade de paisagens. Diversidade de paisagens essa que é ainda mais ampla devido ao fator climático que tende a ser, grosso modo, (i) tropical úmido na porção Sul e Leste do estado, (ii) tropical semiúmido na porção Central e Oeste e, (iii) tropical semiárido na porção Norte. Em termos geomorfológicos merece destaque seu relevo predominantemente movimentado - principalmente em suas porções Sul, Centro e Leste - e sua situação de divisor de águas entre algumas das principais bacias hidrográficas do Brasil extra-amazônico como, por exemplo, as dos rios Paraná, São Francisco, Paraíba do Sul, Doce, Jequitinhonha e Mucuri.

\section{Procedimentos Metodológicos}

O trabalho foi realizado com base em análises cartográficas e de sensoriamento remoto. Inicialmente foram analisados mapas temáticos topográficos e hidrográficos do estado de Minas Gerais. Com base nesses mapas foram identificados os divisores entre as principais bacias hidrográficas do estado. A partir desse momento, com uso de imagens geradas pelo Programa Google Earth, foram realizadas identificações de possíveis capturas fluviais ao longo dos grandes divisores hidrográficos. Procurou-se identificar cotovelos fluviais, vales secos e ou superdimensionados. Nas áreas onde as geoformas acima foram identificadas, foram marcadas as possíveis capturas no mapa para serem testadas na segunda parte. $\mathrm{Na}$ segunda parte foram gerados, então, perfis topográficos das possíveis capturas, passando pelo que provavelmente seria: (i) a área da bacia capturada, (ii) a bacia pirata e (iii) o planalto capturado. Em cada perfil foi analisada a altitude da área possivelmente capturada, altitude média da bacia pirata e da área pirateada. A partir desses métodos foram consideradas possíveis capturas fluviais aquelas que apresentam cotovelo de captura e têm área capturada com altitude mais próxima da bacia pirateada do que da bacia pirata (bacia para onde o curso fluvial drena atualmente). Entretanto, duas exceções a essa regra foram incorporadas, pois apresentavam evidências de cotovelo muito pronunciadas e/ou haviam sido indicadas como tal em outros trabalhos. 


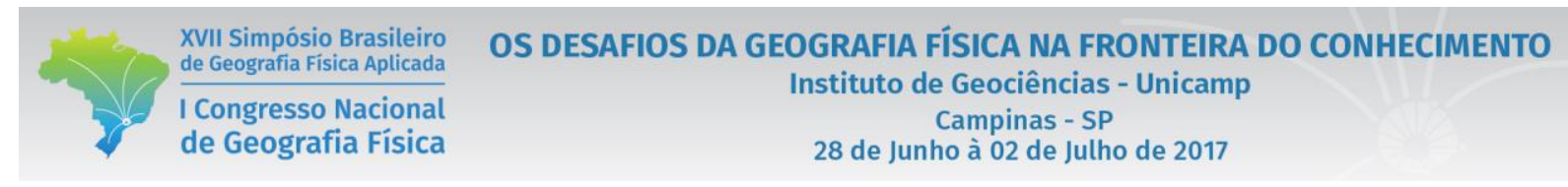

\section{Resultados}

A partir da análise do mapa foram encontrados aproximadamente dez cotovelos que poderiam indicar capturas. Os perfis topográficos mostraram que entre esses dez, sete apresentavam maiores possibilidades de serem importantes capturas fluviais (Figura 1). A tabela 1 mostra que em cinco desses sete casos as áreas capturadas mantém altitude topográfica semelhante a das bacias pirateadas e muito superior as das bacias piratas. Relevante ressaltar que entre essas possíveis sete capturas fluviais, quatro estão nos limites entre a bacia do Paraná com a do São Francisco contra apenas uma entre o Paraná com o Doce, uma entre Jequitinhonha e Mucuri e uma no tríplice divisor Jequitinhonha-Doce- São Francisco (Figura 1).

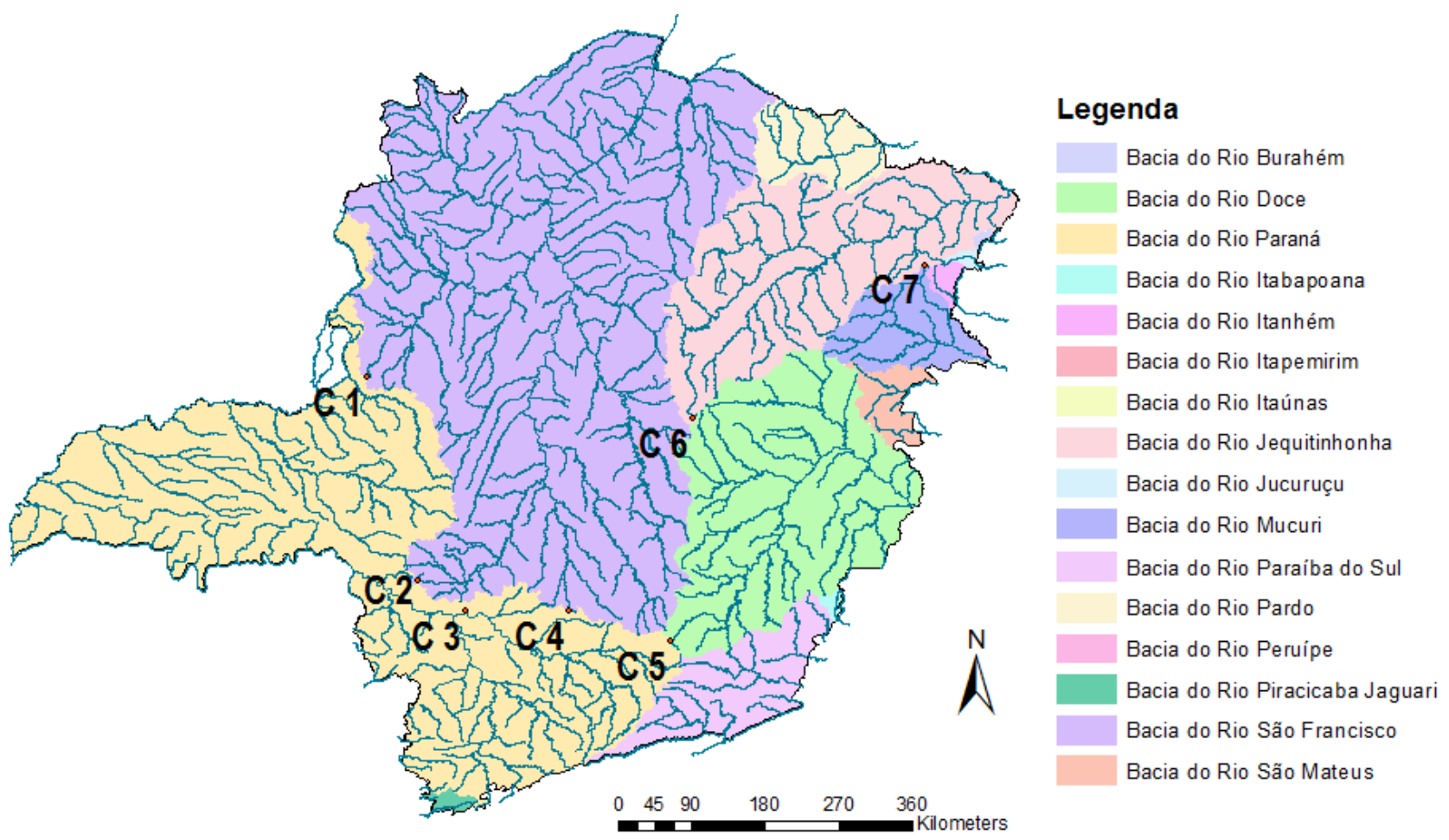

Figura 1 - Mapa de Minas Gerais mostra a localização das possíveis capturas encontradas. Banco de dados: IGAM e ANA. 
XVII Simpósio Brasileiro de Geografia Fisica Aplicada

I Congresso Nacional de Geografia Física
OS DESAFIOS DA GEOGRAFIA FÍSICA NA FRONTEIRA DO CONHECIMENTO

Instituto de Geociências - Unicamp

Campinas - SP

28 de Junho à 02 de Julho de 2017

Tabela I - Comparação da altitude da área capturada com as bacias relacionadas

\begin{tabular}{|c|c|c|c|}
\hline Captura & $\begin{array}{c}\text { Altitude do planalto supostamente } \\
\text { capturado }\end{array}$ & $\begin{array}{c}\text { Altitude média da bacia } \\
\text { pirata }\end{array}$ & $\begin{array}{c}\text { Altitude média da bacia } \\
\text { pirateada }\end{array}$ \\
\hline 1 & $983-900$ & $743-708$ & $980-900$ \\
\hline 2 & $1395-1250$ & $1008-760$ & $1400-1290$ \\
\hline 3 & $987-762$ & $1107-985$ & $795-662$ \\
\hline 4 & $1023-945$ & $896-822$ & $1052-976$ \\
\hline 5 & $1096-1190$ & $870-760$ & $1286-1115$ \\
\hline 6 & $1212-1040$ & $1231-1086$ & $1210-722$ \\
\hline 7 & $518-669$ & $320-480$ & $590-700$ \\
\hline
\end{tabular}

No caso da bacia do Doce com o Paraná e no tríplice divisor hidrográfico, em conformidade com o que já está consagrado na literatura para margens passivas (Cherem et al., 2012a; 2012b; 2013; Salgado et al., 2012; 2014, 2015) ficou comprovado que as bacias costeiras (Paraíba do Sul, Doce, Mucuri e Jequitinhonha) piratearam área das bacias continentais (Paraná e São Francisco). Nas outras quatro capturas, três vezes o rio São Francisco pirateia o Paraná e uma vez o contrário ocorre (captura 3). Entretanto, a Captura 3 (Figura1 e Tabela 1) é um caso especial. Trata-se possivelmente de um processo antigo que teria permitido ao rio Paraná capturar toda uma enorme área (dezenas de milhares de quilômetros quadrados) que pertenceria ao rio São Francisco. Nesse caso, a atual principal nascente do rio Paraná - o Rio Grande - seria a nascente original do rio São Francisco. A se confirmar essa captura, ela seria a maior do Brasil e uma das principais já identificadas no mundo, pois significaria uma profunda mudança na rede de drenagem dos rios São Francisco e Paraná, dois entre os 50 principais rios do mundo. Tal possível captura foi sugerida inicialmente por Rezende (2016). Entretanto, esse mesmo autor entende que a mesma deva ser melhor investigada, pois não está bem caracterizada e, se realmente ocorreu, seria muito antiga e um tanto desconfigurada pelo passar do tempo geológico.

\section{Considerações finais}

Percebe-se através desse trabalho que capturas fluviais são fenômenos relativamente comuns em Minas Gerais. Em maior nível de detalhamento provavelmente seriam encontradas muito mais ocorrências desse fenômeno do que as sete aqui preliminarmente identificadas. Os resultados encontrados permitem ainda inferir uma possível mega captura fluvial e, sendo assim, demonstram que o assunto é rico e deve ser aprofundado para além desse estudo preliminar. 


\section{Referências}

CHEREM, L. F.; VARAJÃO, C. A. C.; SALGADO, A. A. R.; VARAJÃO, A. F. D.; BRAUCHER, R.; BOURLÈS D.; MAGALHÃES JÚNIOR, A. P.; NALINI JUNIOR, H. A. Denudação química e rebaixamento do relevo em bordas interplanálticas com substrato granítico: dois exemplos no SE de Minas Gerais. Revista Brasileira de Geomorfologia, v. 13, p. 73-84, 2012.

CHEREM, L. F. ; VARAJÃO, C. A. C. ; BRAUCHER, R., BOURLÈS D., SALGADO, A. A. R., VARAJÃO, A. F. D. Long-term evolution of denudational escarpments in southeastern Brazil. Geomorphology , v. 173, p. 118$127,2012$.

CHEREM, L. F. S.; VARAJÃO, C. A. C.; JÜNIOR, A. P. M.; VARAJÃO, A. F. D. C.; SALGADO, A. A. R.; OLIVEIRA, L. A. F.; BERTOLINI, W. Z. O papel das capturas fluviais na morfodinâmica das bordas interplanálticas do sudeste do Brasil. Revista Brasileira de Geomorfologia, v.14, n.4, p.299-308, 2013.

REZENDE, E. A. O papel da dinâmica espaço-temporal da rede hidrográfica na evolução geomorfológica da alta/média bacia do Rio Grande. 2016, Qualificação de doutorado em Geologia Ambiental e Recursos Naturais Escola de Minas, Departamento de Geologia, Universidade Federal de Ouro Preto, Ouro Preto.

SALGADO, A. A. R.; SOBRINHO, L.C.; CHEREM, L. F. ; VARAJÃO, C. A. C. ; VARAJÃO, C. A. C. ; BOURLÈS, D. L. ; BRAUCHER, R. ; MARENT, B. R. Estudo da evolução da escarpa entre as bacias do Doce/Paraná em Minas Gerais através da quantificação das taxas de desnudação. Revista Brasileira de Geomorfologia, v. 13, p. 213-222, 2012.

SALGADO, A. A. R.; MARENT B. R. ; CHEREM L. F. ; BOURLÉS, D. ; SANTOS, L. J. C. ; BRAUCHER, R ; BARRETOS, H. N. Denudation and retreat of the Serra do Mar escarpment in southern Brazil derived from in situ-produced ${ }^{10}$ Be concentration in river sediment. Earth Surface Processes and Landforms, v. 39, p. 311-319, 2014.

SALGADO, ANDRÉ AUGUSTO RODRIGUES; REZENDE, ERIC DE ANDRADE ; BOURLÈS, DIDIER ; BRAUCHER, RÉGIS ; DA SILVA, JULIANA RODRIGUES ; GARCIA, RICARDO ALEXANDRINO. Relief evolution of the Continental Rift of Southeast Brazil revealed by in situ-produced 10Be concentrations in river-borne sediments. Journal of South American Earth Sciences JCR, v. 67, p. 89-99, 2016. 